\title{
New insights into the apple fruit dehydration process at the cellular scale by 3D continuum
}

modeling

Kevin Prawiranto ${ }^{\mathrm{a}, \mathrm{b}, \mathrm{c}}$, Thijs Defraeye ${ }^{\mathrm{a}, \mathrm{c} *}$, Dominique Derome $^{\mathrm{c}}$, Pieter Verboven ${ }^{d}$, Bart Nicolai ${ }^{d, e}$, Jan Carmeliet $^{\mathrm{b}, \mathrm{c}}$

${ }^{a}$ Empa, Swiss Federal Laboratories for Materials Science and Technology, Laboratory for Biomimetic Membranes and

Textiles, Lerchenfeldstrasse 5, 9014 St. Gallen, Switzerland

${ }^{b}$ Swiss Federal Institute of Technology Zurich (ETHZ), Chair of Building Physics, Stefano-Franscini-Platz 5, 8093 Zurich, Switzerland

${ }^{c}$ Empa, Swiss Federal Laboratories for Materials Science and Technology, Laboratory for Multiscale Studies in Building Physics, Uberlandstrasse 129, 8600 Dübendorf, Switzerland

${ }^{d}$ KU Leuven - University of Leuven, Division MeBioS, Postharvest Group, Willem de Croylaan 42, 3001 Heverlee, Belgium ${ }^{e}$ VCBT, Flanders Centre of Postharvest Technology, Willem de Croylaan 42, 3001 Heverlee, Belgium

* Corresponding author.

Address: Laboratory for Biomimetic Membranes and Textiles, Empa, Lerchenfeldstrasse 5, 9014 St. Gallen, Switzerland

Email: thijs.defraeye@empa.ch

Telephone: + 41587654790

Fax: +41587656909

Accepted Manuscript:

Kevin Prawiranto, Thijs Defraeye, Dominique Derome, Pieter Verboven, Bart Nicolai, Jan Carmeliet, New insights into the apple fruit dehydration process at the cellular scale by $3 \mathrm{D}$ continuum modeling, Journal of Food Engineering, Volume 239, 2018, Pages 52-63, ISSN 0260-8774

https://doi.org/10.1016/j.jfoodeng.2018.06.023.

(http://www.sciencedirect.com/science/article/pii/S0260877418302735)

This manuscript version is made available under the CC-BY-NC-ND 4.0

1icense http://creativecommons.org/1icenses/by-nc-nd/4.0/ 


\begin{abstract}
An accurate understanding of the dehydration kinetics of biological materials is essential to optimize their dehydration processes and to produce high-quality dried products. For a soft, cellular material like fruit, the underlying mass transport and deformation mechanisms at the cellular scale play a key role here. To improve our insight into the cellular scale dehydration kinetics, a 3D model is developed to quantify the impact of the changes in the cellular structure of apple (parenchyma) cells during dehydration on the tissue sorption isotherm and water permeability. As a step beyond the current stateof-the-art models, the model incorporates the changes in the cellular structure over entire dehydration process, starting from a turgid cell down to the occurrence of (free) shrinkage, plasmolysis (detachment of the cell membrane from the cell wall) or lysis (rupture of the cell membrane). Regarding the tissue sorption isotherm, plasmolysis induced a reduction in the equilibrium water content (up to 60\%) compared to the free-shrinkage or lysis cases at the same water activity level. On the other hand, the tissue water permeability was found to increase up to five times when lysis occurs, compared to free shrinkage or plasmolysis. A parametric study also quantified the dependency of tissue permeability on the cell wall thickness, the cell membrane permeability, the cell size and the elongation aspect ratio of the cell. We identified that the dehydrated, shrunken cellular tissue reduces the outgoing water flux compared to fresh tissue for the same water potential gradient. As such, dehydrated tissue forms a barrier against further moisture removal from the fresh tissue below.
\end{abstract}

Keywords: fruit, dehydration, microscale model, water transport, water permeability, sorption isotherm 


\section{Introduction}

Dehydration is a common method used to extend the shelf life of fresh fruit and to produce alternative healthy snacks (Devahastin \& Niamnuy 2010). The enzymatic activity and possible spoilage (e.g., mold growth) can be restricted by decreasing the water activity of the fruit (Mossel 1975). The dehydration process during which this water activity is reduced, however, considerably defines the final fruit quality, such as nutritional value, color degradation (browning), texture and rehydration capacity (Labuza 1972; Eichner 1975; Ratti 2001; Omolola et al. 2015). Several of the quality attributes are in direct relation with the physical properties of the product, such as porosity and bulk density (Krokida \& Maroulis 1997; Perera 2005). To design a dehydration method that can yield good quality product, a proper understanding of the underlying mechanisms involved in the fruit dehydration process is essential.

Fruit tissue is a deformable, cellular material (Naiqian \& Pitts 1999). The fruit cellular structure generally consists of the protoplast (which contain vacuole and cytoplasm), the cell wall, the cell membrane and the intercellular space (Figure 1). The dehydration of cellular structure leads to a significant deformation of the bulk tissue. Figure 2 shows the schematic of the dehydration mechanisms of a turgid (fresh) cell. Under turgid conditions, a hydrostatic (turgor) pressure acts at the interior of the cell wall and maintains the rigidity of the cell structure. The dehydration of a turgid cell leads to the shrinkage of the protoplast and a decrease of the turgor pressure. The change of water content in the cell is proportional to its global volume change, known as free shrinkage (Mayor \& Sereno 2004). The cell shrinks until it reaches the zero turgor point (condition II in Figure 2). Water loss beyond the zero turgor point induces several responses depending on the initial shape and size of the cell, the viscosity of the protoplast and the environmental conditions (Oparka 1994). There are three typical dehydration responses of a fruit cell after losing its turgor pressure (condition III in Figure 2) (Seguí et al. 2010; Lang et al. 2014). The first response is free shrinkage (condition IIIa in Figure 2), which means that the cell and protoplast can continue to shrink in an unrestricted way. The second one, plasmolysis, is observed when the cell membrane detaches from the cell wall (condition IIIb in Figure 2), either completely or partially. In the third case, lysis, the cell membrane breaks and detaches from the cell wall (condition IIIc in Figure 2). 
These changes in the cellular structure directly affect the macroscopic transport properties, such as water permeability of the tissue, and thereby also the drying kinetics (Mebatsion et al. 2008; Halder et al. 2011; Ho et al. 2013). Several numerical studies using microscale models were carried out to better understand the mass transport and the associated deformation at the cellular scale during dehydration. Recently, 2D models using the Finite Element Method (FEM) have been used to calculate macroscopic gas transport properties of pear (Ho et al. 2013) and water transport properties of pear (Fanta et al. 2013) and apple (Aregawi et al. 2014). A water transport model also has been coupled with a micromechanics model to evaluate dehydration-driven microstructural changes of fruit tissue (Abera et al. 2013; Aregawi et al. 2014; Fanta et al. 2013). Although this 2D coupled model allowed to monitor cell dehydration and its associated microstructural changes, its application was limited to conditions in the high water activity range so when the cells are still in turgid condition. A meshless 2D model has been developed to study the micromechanics that govern the microstructural change of apple cells during dehydration, by coupling Smoothed Particle Hydrodynamics (SPH) modeling of the cell protoplast with Discrete Element Method (DEM) modeling of the cell wall (H. C P Karunasena et al. 2014; H.C.P. Karunasena et al. 2014; Karunasena et al. 2015). In contrast with the FEM-based models, this particle-based model can capture larger cellular deformations with their associated effects, such as cell wall wrinkling. However, the model simplified the water transport mechanisms to some extent as the cell wall permeability is kept constant during dehydration and the effect of the moist intercellular air space on the water transport is not taken into account (Rathnayaka Mudiyanselage et al. 2017). A cellular-scale model that can model the changes in the cellular structure during the entire dehydration process (Figure 2, condition III), and the impact on the water transport, is not yet developed.

This study aims to improve our understanding of microstructural changes of fruit cells during dehydration and their impact on the macroscopic water transport properties of the bulk tissue. To this end, a 3D microscale water transport model is developed to incorporate the changes of the cellular structure during dehydration down to very low water activities. Hence, it enables us to capture the effects of free shrinkage, plasmolysis and lysis. The model is used afterward to derive the macroscopic water transport properties of the fruit tissue, namely the tissue water permeability and sorption isotherm. 
A parametric study is performed to assess the relative impact of model parameters on the tissue permeability, including the water permeability of the cell membrane, cell wall thickness, initial cell size, dry matter content of the protoplast and cell geometry. Apple tissue is chosen to represent the fruit tissue, as dried apple is among the most consumed dried fruits in some parts of the world, including the EU (CBI 2008). 


\section{Materials and methods}

First, a representative geometry of the microscale cellular tissue is presented. Next, the mathematical model of water transport in the cellular structure is described. Subsequently, the way in which the model captures the changes in the cellular structure during dehydration is discussed. Finally, the computational method and the parametric study are presented.

\subsection{Geometrical representation of cellular fruit tissue}

Apple cortex tissue consists of thin-walled parenchyma cells (Khan \& Vincent 1990; Gibson 2012). The variability in size and shape of those cells is considerably large, mainly due to cultivar differences. Herremans, Verboven, Hertog, et al. (2015) showed that fresh Braeburn, Kanzi, and Jonagold apple cells have an average diameter ranging from 170 to $220 \mu \mathrm{m}$. The cell wall thickness varies in the range of 1-10 $\mu \mathrm{m}$, depending on the cultivars (Ben-Arie et al. 1979; Mebatsion et al. 2009; Joardder et al. 2015). An investigation using SEM (Lewicki \& Porzecka-Pawlak 2005) indicates that the cell shape is closer to a polyhedron than a sphere. The cell shape is commonly defined by its shape factor, which is the ratio of the surface area of a sphere with that of a cell having the same volume as the sphere. The porosity of fresh apple tissue, defined as the ratio of the intercellular air space volume to the total tissue volume, is found to be in the range of $18 \%$ to $25 \%$ (Herremans, Verboven, Verlinden, et al. 2015). Based on the details above, a representative cellular model structure of apple fruit tissue is constructed (Figure 3). It is assumed that an apple cell is a cuboctahedron with a shape factor of 0.90 . The regular arrangement of cuboctahedral cells leads to an overall porosity of $19 \%$.

A typical parenchyma cell consists of intracellular parts (vacuole, tonoplast membrane, cytoplasm and cell membrane) and outer cellular parts (cell wall and intercellular air space). The water permeability of the tonoplast, a membrane that separates vacuole and cytoplasm, is significantly higher (up to 100 times) than that of the cell membrane (Maurel 1997; Seguí et al. 2006). Therefore, in the model, cytoplasm, tonoplast and vacuole are considered as one component, which is called protoplast. The protoplast is enclosed within the cell membrane. The other modeled components are the cell wall and the intercellular air space (Figure 1). The initial edge length $l_{0}$ (Figure 3) of a fresh apple cell is set at 
$200 \mu \mathrm{m}$, which corresponds to the average equivalent diameter of cells of Braeburn and Jonagold apples (Herremans et al. 2013).

\subsection{Water transport model at the cellular scale}

The basic concepts of the model which is made to determine the tissue water permeability and sorption isotherm of apple tissue are described in the following sections. Here, the tissue water permeability (or conductivity) is a macroscopic parameter that quantifies the ability of fruit tissue in transporting water both in the liquid and vapor phase. It takes into account all possible water transport mechanisms at the cellular scale, including vapor diffusion and liquid flow, and lumps them in a single transport variable. More details on the used model can be found in (Fanta et al. 2013; Aregawi et al. 2014). The simulations are carried out under isothermal conditions.

\subsubsection{Conservation equations}

The following conservation equation for water transport, based on Fick's second law of diffusion, is solved for each of the cellular components:

$$
\frac{\partial\left(\rho_{d m, i} x_{i}\right)}{\partial t}=\nabla \cdot \rho_{d m, i} D_{i} \nabla x_{i}
$$

where $x_{i}$ is the dry base water content $\left[\mathrm{kg} \mathrm{kg}^{-1}\right], \rho_{d m, i}$ is the dry matter density $\left[\mathrm{kg} \mathrm{m}^{-3}\right], D_{i}$ is the water diffusivity $\left[\mathrm{m}^{2} \mathrm{~s}^{-1}\right]$ of cellular component $i$. In this study, the water potential $\psi[\mathrm{Pa}]$ is taken as the driving force to solve the water transport in the cellular structure. The water potential $\psi_{i}$ and water content $x_{i}$ are related to through the water capacity $C_{\psi, i}$ :

$$
C_{\psi, i}=\frac{\partial x_{i}}{\partial \psi_{i}}
$$

Substituting Equation (2) into Equation (1) and assuming steady state condition leads to:

$$
\nabla \cdot\left(K_{i} \nabla \psi_{i}\right)=0
$$

where $K_{i}$ is the water permeability of the cellular component $i$ [s], which equals:

$$
K_{i}=\rho_{d m, i} D_{i} C_{\psi, i}
$$

The following sections discuss the formulation of the water permeability of each cellular component in detail. The water permeability of each cellular component as a function of water potential is plotted in 
Figure 4. It is calculated by solving the conservation and constitutive equations of each respective component, by using the corresponding material properties. Note that these material properties of apple fruit typically vary due differences in cultivar, ripeness level, cultivation sites or harvest year, amongst others, which introduce a biological variability. The impact of these differences in cellular structure and corresponding material properties on the water transport is explored in a parametric study (Section 2.4.2).

\subsubsection{Constitutive equations}

\subsubsection{Protoplast}

In the protoplast, water is present as a liquid. The water permeability of the protoplast depends on the dry matter density $\rho_{d m, c}\left[\mathrm{~kg} \mathrm{~m}^{-3}\right]$, water diffusivity $D_{c}\left[\mathrm{~m}^{2} \mathrm{~s}^{-1}\right]$, water capacity $C_{\psi, c}\left[\mathrm{~Pa}^{-1}\right]$ and dry base water content $x_{c}\left[\mathrm{~kg} \mathrm{~kg}^{-1}\right]$ of the protoplast, as it is given by (Fanta et al. 2013):

$$
K_{c}=D_{c}\left(\frac{\rho_{d m, c} C_{\psi, c}}{1+x_{c}}\right)
$$

During dehydration, it is assumed that no solute can escape the protoplast. Thus, the dry mass density of the protoplast $\rho_{d m, c}$ increases along with water loss according to (Fanta et al. 2013):

$$
\rho_{d m, c}=\frac{\rho_{d m, c 0}}{1-\left(x_{c 0}-x_{c}\right) \frac{\rho_{d m, c 0}}{\rho_{w}}}
$$

where $\rho_{d m, c 0}$ and $x_{c 0}$ are the initial dry mass density and the water content of the cell protoplast at the beginning of the dehydration process, respectively. The water capacity of protoplast $C_{\psi, c}$ is defined as the change of the dry base water content $x_{c}$ with respect to a change in cell water potential $\psi_{c}$ :

$$
C_{\psi, c}=\frac{\partial x_{c}}{\partial \psi_{c}}
$$

The water potential of the protoplast $\psi_{c}$ is the sum of the osmotic potential $\psi_{s}$ and the turgor pressure $\psi_{p}$. The osmotic potential $\psi_{s}$ has negative value and defines the potential of water molecules to move from a high (less solute, e.g. at $-5 \mathrm{MPa}$ ) to a low water potential (more solute, e.g. at $-50 \mathrm{MPa}$ ) region across a cell membrane. It quantifies the pressure required to prevent such water movement. The turgor pressure 
$\psi_{p}$ is the pressure generated within the cell membrane because of osmotic flow into the protoplast, and its value is positive. The total water potential can be written as:

$$
\psi_{c}=\psi_{s}+\psi_{p}
$$

The derivation of $C_{\psi, c}$ in Equation (7) is presented in Section 2.3, where different cases of cellular dehydration states are explained. By considering the protoplast as a dilute solution with a solute concentration of less than 1 molar (Yamaki 1984), the osmotic potential can be calculated from the Van't Hoff approximation (Fanta et al. 2013):

$$
\psi_{s}=-\frac{\rho_{w}}{x_{c} M_{s}} R T
$$

where $\rho_{w}$ is the density of water $\left[\mathrm{kg} \mathrm{m}^{-3}\right], M_{s}$ is the solute molar mass in the protoplast $\left[\mathrm{kg} \mathrm{mol}^{-1}\right], R$ is the gas constant $\left[8.314 \mathrm{~J} \mathrm{~mol}^{-1} \mathrm{~K}^{-1}\right]$, and $T$ is the temperature $[\mathrm{K}]$. In this study, the solute molar mass $M_{s}$ is calculated based on the solute composition formulated by (Tortoe et al. 2008).

\subsubsection{Cell wall}

The primary cell wall of parenchyma tissue is regarded as a porous medium predominantly made of cellulose, hemicellulose, and pectin (Gibson 2012; Bidhendi \& Geitmann 2016). At unsaturated conditions, water is present in liquid and vapor form. The dominant mechanisms of water transport in the cell wall are pressure-driven (Darcy) flow, molecular diffusion, and capillary flow (Fanta et al. 2012). In the model, the cell wall permeability (Figure 4) incorporates all the possible transport mechanism in the cell wall. It is defined as (Fanta et al. 2013):

$$
K_{w}=\rho_{d m, w} D_{w} C_{\psi, w}
$$

where $\rho_{d m, w}$ is the dry matter density of the cell wall $\left[\mathrm{kg} \mathrm{m}^{-3}\right], D_{w}$ is the water diffusivity of the cell wall $\left[\mathrm{m}^{2} \mathrm{~s}^{-1}\right]$, and $C_{\psi, w}$ is water capacity of the cell wall $\left[\mathrm{Pa}^{-1}\right]$. The cell wall properties are taken from (Fanta et al. 2012). The desorption isotherm is modeled as:

$$
\ln \left(\frac{\gamma}{a_{w}}\right)=\alpha x_{w}{ }^{-R_{c}}
$$


where $x_{w}$ is the dry base water content of the cell wall $\left[\mathrm{kg} \mathrm{kg}^{-1}\right]$. The quantities $\alpha, \gamma, R_{c}$ are empirical model constants and their values are listed in Table 1 . The water activity $a_{w}$ is related to water potential $\psi$ by:

$$
\psi=\frac{R T \ln \left(a_{w}\right)}{V_{w}}
$$

where $V_{w}$ is the molar volume of water $\left[1.8 \times 10^{-6} \mathrm{~m}^{3} \mathrm{~mol}^{-1}\right]$. The water capacity is described as (Fanta et al. 2013):

$$
C_{\psi, w}=\frac{\partial x_{\psi}}{\partial \psi}=\frac{V_{w} x_{w}{ }^{\left(R_{c}+1\right)}}{\alpha R T R_{c}}
$$

\subsubsection{Intercellular air space}

In the intercellular air space, water exists as vapor, as we assume that no condensation occurs. The water permeability of the air in the cell is given by:

$$
K_{a}=\rho_{d m, a} D_{a} C_{\psi, a}
$$

where $\rho_{d m, a}$ is the dry matter density of air $\left[\mathrm{kg} \mathrm{m}^{-3}\right], D_{a}$ is the diffusivity of water vapor in air $\left[\mathrm{m}^{2} \mathrm{~s}^{-1}\right]$ and $C_{\psi, a}$ is water vapor capacity of air $\left[\mathrm{Pa}^{-1}\right]$.

\subsubsection{Cell membrane}

The cell membrane that encapsulates the cell protoplast is not explicitly discretized in the model. Instead, it is modeled as a thin membrane by including an internal resistance between the protoplast and the cell wall. As such, the water flux $J$ at their interface is defined as (Nobel 2009):

$$
J=\frac{K_{m}}{L_{m}}\left(\psi_{c}-\psi_{a}\right)
$$

where $K_{m}$ is the membrane water permeability [s] and $L_{m}$ is the membrane thickness. $K_{m}$ is related to the osmotic permeability coefficient of the cell membrane, $P_{m}$, by (Nobel 2009):

$$
K_{m}=\frac{\rho_{w} P_{m} V_{w} L_{m}}{R T}
$$


where $\rho_{w}$ is the water density $\left[\mathrm{kg} \mathrm{m}^{-3}\right]$. The permeability of the cell membrane is shown in Figure 4, calculated based on a membrane thickness of $10 \mathrm{~nm}$ (Ho et al. 2014). 


\subsection{Changes of fruit cellular structure during dehydration}

The proposed geometrical model in Figure 3 is used to model the dehydration of a turgid cell until the zero turgor point and the subsequent dehydration mechanisms: free shrinkage, plasmolysis and lysis, as depicted in Figure 2.

\subsubsection{Turgid cell}

The turgid condition is present at high water activity. The turgor pressure has an impact on the sorption isotherm of the protoplast since it contributes to the total water potential, as shown in Equation (6). To determine the turgor pressure in the protoplast at different water activity levels, a shrinkage-expansion simulation of a cuboctahedron cell is performed. The steps of shrinkage-expansion simulation are sketched in Figure 5. First, the initial conditions of a 'fresh' (turgid) cell, i.e. the initial edge length $l_{0}$, the cell wall thickness $t_{w}$ and the protoplast water content $x_{c, 0}$, are set based on the value found in experiments, for example from (Lewicki \& Pawlak 2003; Mebatsion et al. 2009; Herremans, Verboven, Verlinden, et al. 2015). The 'fresh' cell shrinks until it reaches the zero turgor point at $a_{w}=0.97$ (step a in Figure 5). Here, the zero turgor value of water activity is chosen based on the best agreement between the simulation results and the experimental sorption isotherm data in the turgid condition, as discussed in Section 3.2. The water content at the zero turgor point is calculated from the osmotic potential according to Equation (9). Here, the decrease of the protoplast volume is assumed to be equal to the water loss. As such, the protoplast volume at the zero turgor point is determined. Next, an internal turgor pressure $P_{t}$ is applied uniformly on the cell wall (step b in Figure 5) to determine the protoplast volume as a function of the applied turgor pressure $P_{t}$ (step c in Figure 5). The pressure $P_{t}$ is increased stepwise from $0 \mathrm{MPa}$ to $1 \mathrm{MPa}$, which is approximately the range of typical turgor pressures found in several apple cultivars (Lin \& Pitt 1986). From the resulting protoplast volume, the cell water content $x_{c}$ is determined. The corresponding osmotic and total potentials of the protoplast at different water content levels are then calculated using Equation (9) and Equation (8), respectively.

In the expansion simulation, the momentum balance for material undergoing a large deformation is solved at a steady state condition for a given turgor pressure $P_{t}$ (Bonet \& Wood 2008): 


$$
\nabla \cdot\left(\mathbf{S} \cdot \mathbf{F}^{T}\right)=0
$$

where $\mathbf{S}$ " is the second Piola-Kirchhoff stress tensor and $\mathbf{F}^{T}$ is the transpose of the elastic deformation gradient tensor $\mathbf{F}$. The second Piola Kirchhoff stress tensor is defined as a function of the strain energy density $W_{s}$ :

$$
\mathbf{S}=\frac{\partial W_{s}}{\partial \mathbf{E}}
$$

where $\mathbf{E}$ is the elastic Green-Lagrange strain tensor that is described as:

$$
\mathbf{E}=\frac{1}{2}\left(\mathbf{F}^{\mathrm{T}} \mathbf{F}-1\right)
$$

The cell wall is modeled as an isotropic hyperelastic material using a Neo-Hookean model (van der Sman 2015). Here, the strain energy density function is:

$$
W_{s}=\frac{G}{2}\left(\overline{I_{1}}-3\right)
$$

where $G$ is the shear modulus $[\mathrm{Pa}]$, and $I_{l}$ is the first invariant of the elastic right Cauchy-Green tensor. The shear modulus $G$ is determined from the elastic Young modulus $E$ and the Poisson's ratio $v$ :

$$
G=\frac{E}{2(1+v)}
$$

The Young modulus $(52.8 \mathrm{MPa})$ and Poisson's ratio (0.24) of the cell wall are taken from (Naiqian \& Pitts 1999). The initial edge length of the cell under turgor pressure is set to be $200 \mu \mathrm{m}$. The initial water content $(6.54 \mathrm{~kg} / \mathrm{kg})$ was experimentally measured in this study by an oven drying experiment of apple tissue. It is calculated as the ratio of the difference between the initial sample mass and its dry mass after 24 hours oven drying, to the initial sample mass. The initial cell wall thickness is set to $2 \mu \mathrm{m}$. This value is within the range of cell wall thickness $(1-10 \mu \mathrm{m})$ found for several apple cultivars (Ben-Arie et al. 1979; Mebatsion et al. 2009; Joardder et al. 2015).

Figure 6 shows the calculated protoplast sorption isotherm. A polynomial function is fitted to the sorption isotherm curve and the water capacity is then determined to be:

$$
C_{w, c}=\frac{\partial x_{c}}{\partial \psi_{s}}=1.14 \times 10^{-12} \psi_{c}+4.53 \times 10^{-6}
$$




\subsubsection{Free shrinkage}

During free shrinkage, the entire cellular structure shrinks. For model simplification, it is assumed that, as the cell shrinks, it does not change shape (shape factor) during dehydration. The decrease of protoplast volume is equal to the cell water loss. The cell water content can be determined as:

$$
x_{c}=-\frac{\rho_{w}}{\psi_{s} M_{s}} R T
$$

where $\rho_{w}$ is the density of water, $M_{s}$ is the molar mass of solutes in the protoplast, $\psi_{s}$ is osmotic potential, $R$ is the gas constant and $T$ is the temperature. The water capacity of the cell protoplast during plasmolysis is calculated as:

$$
C_{\psi, c}=\frac{\partial x_{c}}{\partial \psi_{s}}=\frac{\rho_{w}}{\psi_{s}^{2} M_{s}} R T
$$

Cell wall deformation, e.g. wrinkling or buckling, is not modeled. However, as the cell wall volume is assumed constant, the cell wall thickness is modeled to increase during dehydration. 


\subsubsection{Plasmolysis}

Plasmolysis is modeled by assuming that the rigid cell wall remains in place during cell membrane shrinkage, where the shrinking protoplast remains positioned in the center of the cell (Figure 2). The gap appearing between the protoplast and the cell wall is assumed to be filled with air. In some cases, as shown by the experiment of (Seguí et al. 2006), some parts of the cell membrane may still be attached to the cell wall. The impact of this phenomenon is further explored in Section 2.4.2. The shrinkage of the protoplast is calculated using the same approach used in the free shrinkage case.

\subsubsection{Lysis}

If the cell membrane breaks, the protoplast fluid is assumed to remain within the cell wall. Therefore, the lysis case is modeled by removing the membrane resistance in the model (Equation (15)). During dehydration, the shrinkage of the cellular structure is calculated using the same modeling approach as used in the free shrinkage case.

\subsection{Computational model}

The model presented above is used to determine the tissue water permeability as a function of water potential and the tissue sorption isotherm. Due to the periodicity of the cellular geometry, a single cell can be used as the modeled system (Figure 7). In a steady state condition, a small gradient of water activity (so water potential) is imposed over the domain by specifying the water activity at the top and bottom boundaries (Dirichlet boundary conditions). The tissue water permeability, $K[\mathrm{~s}]$ is calculated as:

$$
K(\psi)=-J \frac{L}{\left(\psi_{1}-\psi_{2}\right)}
$$

where $J$ is the total steady-state flux over the entire cellular structure $\left[\mathrm{kg} \mathrm{m}^{-2} \mathrm{~s}^{-1}\right],\left(\psi_{l^{-}}-\psi_{2}\right)$ is the applied water potential difference over the top and bottom boundaries [Pa] and $L$ is the thickness of the simulated cellular structure $[\mathrm{m}]$. In this case, Neumann boundary conditions are not chosen since if the flux is specified, the resulting water activity difference over the domain cannot be controlled. Therefore, determining the water permeability as a function of the water activity becomes less straightforward. 
It is assumed that the liquid water and water vapor in the cell wall and the water vapor in the intercellular space are in equilibrium. Hence, local equilibrium of water activity is imposed at the cell wall-intercellular space boundary, as well as at the cell wall-intracellular space boundary (plasmolysis case). The tissue water permeability $K$ can be related to the effective water diffusivity $D\left[\mathrm{~m}^{2} \mathrm{~s}^{-1}\right]$ in the tissue via the water capacity $C\left[\mathrm{~Pa}^{-1}\right]$ :

$$
D=\frac{K}{\rho_{d m} C}
$$

Note that the water permeability and corresponding effective diffusivity lump all possible transport mechanisms of liquid water and vapor in the cellular structure. The tissue sorption isotherm is derived from the microscale simulations by averaging the water content of the three cellular components (protoplast, cell wall, and intercellular air space) at a given water activity according to their volume fractions. This procedure is started from a cell at turgid conditions and is continued for the three cases of cell dehydration. In this study, the base case is simulated first. Next, a parametric study explores the impacts of water permeability of the cell membrane, cell wall thickness, initial cell size, dry matter content of the protoplast and cell geometry on the tissue permeability. 


\subsubsection{Base case}

To calculate the tissue water permeability of a turgid cell undergoing free shrinkage, plasmolysis or lysis, we assume that the cell is in a steady-state condition and subject to small water potential gradients (equal to differences of 0.001 of water activity), as determined by (Fanta et al. 2013). In that way, the tissue water permeability for over 50 water activity levels was determined. In the turgid condition, the water activity $a_{w}$ was varied from 0.99 , down to the zero turgor point at $a_{w}=0.97$, with decrements of 0.001. For the free shrinkage, plasmolysis, and lysis cases, $a_{w}$ was varied from 0.97 until 0.60 , with 0.01 decrements. For each simulation, water activities which are 0.0005 higher $\left(\psi_{1}\right)$ and 0.0005 lower $\left(\psi_{2}\right)$ than the target water activity were imposed at the top and bottom boundaries, respectively. The computational domain and the boundary conditions for the base case are illustrated in Figure 7 . The relevant material properties for the base case are specified in Table 1. 


\subsubsection{Parametric studies}

\subsubsection{Variation of cell geometry}

Four cell geometries are evaluated to investigate the sensitivity of the tissue permeability to the cell shape, which is non-uniform in nature. Three cylinders with elongation aspect ratio $a$ of 1,2 and 4 are evaluated and compared to the cuboctahedron, which is used for the base case (Figure 8). Here, the elongation aspect ratio $a$ is defined as the ratio of the height $h$ of the geometry to the edge length $l$ (in the cuboctahedron) or diameter $d$ (in the cylinders). Cylinders with $a$ of 1,2 and 4 have a shape factor of $0.87,0.83$, and 0.80 , respectively. Those cell geometries are constructed in such a way that each of them has the same amount of protoplast, cell wall and intercellular space volume as the base case. Hence, the porosity is the same for all of the geometries.

\subsubsection{Model parameters}

A parametric study is performed to evaluate the impact of several model parameters on the tissue permeability. These parameters are: water permeability coefficient of the cell membrane, cell wall thickness, initial cell size and dry matter content of the protoplast. In literature (Joardder et al. 2015; Seguí et al. 2006; Ferrando \& Spiess 2002; Moshelion et al. 2004), these parameters were found to vary significantly between individual fruits of the same cultivar, and between different cultivars. The range of values for each parameter is chosen based on typical values found in literature. The lysis case is not included when looking at the impact of the cell membrane since the membrane is considered ruptured and does not restrict mass transport anymore.

\subsubsection{Different plasmolysis mechanisms}

According to plasmolysis observations by Seguí et al. (2010), the cell membrane detaches from the cell wall either completely or partially. In this section, the impact of the membrane detachment mechanisms on the tissue permeability is investigated. The permeability of a cell undergoing partial plasmolysis with a protoplast attached to the bottom or the side of the cell wall, relative to the direction of water transport, is compared to complete plasmolysis used in the base case, as shown in Figure 9. The permeability is calculated at five water activity levels: 0.976, 0.970, 0.958, 0.928 and 0.795 , which 
correspond to protoplast water content $x_{c}$ of $0.83,0.67,0.50,0.33$ and 0.17 of the initial water content $x_{c, 0}$.

\subsection{Numerical simulations}

The simulations were performed using the finite element software Comsol Multiphysics (version 5.2a). Only one-fourth of the cellular structure needed to be modeled due to symmetry. Based on a mesh sensitivity analysis, the cellular domains are meshed using 55210 tetrahedral elements. Particular refinement is applied in the cell wall domain as it has a relatively small thickness compared to the protoplast and the intercellular air space. The governing equations of water transport for each cellular component were implemented in the coefficient form PDE interface and were solved using linear shape functions. A direct MUMPS solver was adopted to solve the resulting systems of equations. The simulations took roughly $30 \mathrm{~min}$ for each dehydration case on a $2.50 \mathrm{GHz} 8$-core Intel Core i7 processor with 32 GB RAM. 


\section{Results}

\subsection{Sorption isotherms and permeability: comparison with experimental data}

The calculated sorption isotherm of the base case is compared to the experimental data of (KaymakErtekin \& Gedik 2004; Mrad et al. 2012; Aregawi et al. 2013) (Figure 10). The simulations start with the dehydration of a turgid cell until it reaches the zero turgor point. Because there is a lack of information about the exact value of the zero turgor point in literature, the used zero turgor point $\left(a_{w}=\right.$ 0.97) was determined in such a way that the best agreement of calculated and experimental sorption isotherm data is obtained in the turgid region. Below the zero turgor point, the three dehydration cases (free shrinkage, plasmolysis and lysis) are evaluated. The free shrinkage and lysis cases show a good agreement with the experimental data. Their sorption curves are similar since the assumed shrinkage mechanisms are the same. However, the plasmolysis case predicts lower water contents. This is due to the formation and growth of the intracellular space that reduces the water capacity. Nevertheless, the weighted average of the sorption isotherm of the three cases (dotted line) still lies within the range of experimental data.

The calculated water permeability of apple tissue as a function of water potential is presented in Figure 11a. The maximum and minimum value of tissue permeability of each dehydration case in the range of water activities simulated, are tabulated in Table 2. In turgid conditions, the tissue water permeability decreases rather linearly (in a semi-log plot) with water potential. Once the cell undergoes free shrinkage, plasmolysis or lysis, the permeability shows a clear nonlinear dependency on water potential. The substantial differences between the three dehydration cases below turgid condition indicate that the dehydration mechanism has a large impact on the permeability. In all cases, the tissue permeability typically reduces with one order of magnitude from fresh tissue to completely dehydrated tissue (Table 2). In the lysis case, the breakdown of the cell membrane leads to a sudden increase of permeability up to five times higher than the tissue permeability at zero turgor point, as indicated by the blue-dashed line in Figure 11a. In the lower range of water potential, the permeability of the lysis and free shrinkage cases are both decreasing towards a similar value, and approximate the cell wall permeability. The intersection of the plasmolysis permeability curve with both the free shrinkage and lysis permeability at 
low water potential is caused by the increasing volume of intracellular air, resulting in a tissue permeability that approaches the one of air $\left(3.72 \times 10^{-15} \mathrm{~s}\right)$.

It should be noted that the resulting mass flux (mass loss from the dehydrated tissue) is not only dependent on the calculated tissue permeability, but is also proportional to the cell length at a given water potential, as shown by Equation (25). The cell length changes during dehydration as a result of the shrinkage that occurs, hence reducing the pathway for the water to travel through the tissue. The relative change of the cell length, relative to its initial length $\left(L / L_{0}\right)$ for each dehydration case is depicted in Figure $11 \mathrm{~b}$. The cell length in the plasmolysis case does not change during dehydration. In the lysis and free shrinkage cases, the cell length decreases due to the shrinking protoplast. In both cases, $L / L_{0}$ approaches 0.62 which is the cell length ratio when the protoplast is completely dehydrated. The minimum $L / L_{0}(0.04)$, depicted in Figure 11b, is defined as when the cells would collapse fully. In this case, the cell length is the sum of the initial cell wall thickness at the top and bottom of edges of the cuboctahedral cell.

Despite the decreasing permeability with increasing dehydration state, the associated reduction in cell length, so the transport pathway, will have a counteracting effect on the water flux. To identify clearly the impact of the dehydrated cellular structure on the changes in dehydrating water flux, and not permeability, a mass transfer coefficient (MTC) is defined. It is the permeability $K$ divided by the cell length $L$ and is depicted in Figure 11c. For the turgid case where the MTC is constant as the increase of permeability is linear with the increase of cell length. It can be seen that the profiles of MTC in the free shrinkage, plasmolysis, and lysis cases still show similar behavior as of the corresponding permeabilities. Nevertheless, the reduction in cell length with about $40 \%$ (Figure $11 \mathrm{~b}$ ) makes that the water flux is not reduced that much, compared to when only considering the permeability. In any case, the dehydrated, shrunken cellular tissue exhibits a reduced water flux, compared to fresh tissue, for the same water potential gradient. This dehydrated tissue hence forms a kind of barrier against further moisture removal from the fresh tissue below. 
To be able to compare the calculated macroscopic water permeability with experimental data available in the literature, the permeability is converted to an effective diffusivity according to Equation (27). The maximum and minimum value of MTC and effective diffusivity of each dehydration case in the range of water activity simulated are tabulated in Table 2 . Figure $11 \mathrm{~b}$ displays the relation of effective diffusivity with water content. In all three dehydration cases, effective diffusivity shows a strong dependency on tissue water content. In general, tissue at lower water content tends to have higher effective diffusivity, which is caused by the low water capacity of all cellular components. Similar trends are reported in the drying experiment of apple slices (Ramirez et al. 2011) and other fruits and vegetables (Bal et al. 2010; Younis et al. 2018). In the lysis case, the effective diffusivity becomes five times higher after the cell membrane breaks. In all of the dehydration cases, the calculated effective water diffusivities fall within the orders of magnitude of typical values measured in experiments. It can vary from $1 \times 10^{-11}$ to $1 \times 10^{-8} \mathrm{~m}^{2}$ $\mathrm{s}^{-1}$ (Velić et al. 2004; Vega-Galvez et al. 2012; Kaya et al. 2007; Zlatanović et al. 2013).

\subsection{Parametric study on the impact of cell shape, cellular structure and dehydration mechanisms on tissue permeability}

\subsubsection{Cell shape}

Four cell geometries, a cuboctahedron and three cylinders with elongation ratios $a$ of $0.5,1$ and 2, are evaluated as possible building blocks of the fruit tissue. Their permeability is compared and presented in Figure 12. Only the free shrinkage results are shown here since the plasmolysis and lysis results showed the same trends (results not reported). The change of the cell shape does not affect the tissue permeability significantly when the elongation ratio is similar to the cuboctahedron, for example for cuboctahedron versus cylinder with $a=1$. However, a small change is observed when the elongation ratio of the cylinder is changed. Given that the mass transport occurs in the direction parallel to the height of the cell, a cell that has higher elongation ratio transports water easier as most of the water is transported through the protoplast. On the other hand, when a cell has low elongation ratio, the water is transported to a larger extent through the cell wall and intercellular space, which each have a lower permeability than the protoplast. As a result, the permeability decreases with lower cell elongation ratio. However, the reported variations are still quite limited. 


\subsubsection{Cellular structure}

The impact of cell wall thickness, membrane permeability coefficient, dry matter density and initial cell size on the tissue permeability is shown in Figure 13. Figure 13a shows that the higher the water potential becomes, the larger the impact of the membrane permeability coefficient is on the tissue permeability. At a water potential of $-4 \mathrm{MPa}$, the change of membrane permeability from 5 to $300 \mu \mathrm{m} / \mathrm{s}$ causes an increase of tissue permeability of a factor 8 . At low water potential $(>-50 \mathrm{MPa})$, the change of cell membrane permeability does not have an impact on the tissue permeability.

Both in the free shrinkage and lysis cases, the cell wall thickness significantly affects the tissue permeability, especially at low water potential (Figure 13b). In the lysis case, the tissue permeability decreases up to $50 \%$ when the cell wall thickness increases from 0.5 to $10 \mu \mathrm{m}$ at the water potential of $50 \mathrm{MPa}$. In the free shrinkage case, however, the tissue permeability increases with cell wall thickness at high water potential $(>-8 \mathrm{MPa})$, due to a sharp change of cell wall permeability at this condition, as shown in Figure 4. For each cell wall thickness, the lysis case permeability is approaching of that of free shrinkage case when the water potential is low $(>-40 \mathrm{MPa})$. This confirms that the cell membrane plays a less significant role in preventing the water loss from the cell interior, when the cell is severely dehydrated.

The dry matter density of the protoplast has almost no impact on the tissue permeability (Figure 13c) for all of the dehydration cases. The change in dry matter density slightly alters the protoplast permeability, which is not a determining factor for the tissue water permeability. Figure $13 \mathrm{~d}$ indicates that the initial cell size has a notable impact on the tissue permeability over the entire water potential range. This is due to the different ratios of cell wall and protoplast volumes to the total cell volume. With the same initial cell wall thickness $t_{w, 0}$, a larger cell has a lower cell wall volume ratio and a higher protoplast volume ratio than a smaller cell. Therefore, since the cell wall has a higher moisture transport resistance than the protoplast, a larger cell has a higher permeability than a smaller cell. A cell with a radius of $150 \mu \mathrm{m}$ has permeability twice as high as one with a radius of $50 \mu \mathrm{m}$. 


\subsubsection{Plasmolysis mechanisms}

The comparison of tissue permeability between complete plasmolysis and partial plasmolysis cases (Figure 9) is shown in Figure 14. In general, complete plasmolysis and bottom-attached plasmolysis have a similar permeability. The side-attached plasmolysis has a higher permeability than the two other cases, due to the existence of the highly permeable pathway via the protoplast. In contrast, the water permeability is more constant in complete plasmolysis and bottom-attached plasmolysis at low water potentials. Here, the resistance along the flow direction is more constant across the water potential range, as the water needs to pass through all of the cellular components and no bypass is possible. As the protoplast volume is getting smaller (at very low water content or low $a_{w}$ ), its influence on the water permeability of the tissue becomes similar for all three plasmolysis mechanisms.

\section{Discussion and outlook}

A 3D microscale continuum model was developed to better understand the impact of changes in the cellular structure during dehydration on the apple tissue permeability and the sorption isotherm. The novelties of the proposed cellular-scale model, compared to previously developed microscale models, are the fact that the entire cellular dehydration process is modeled, including turgid cells, free shrinkage, plasmolysis and lysis dehydration mechanisms. In addition, a 3D model was made instead of the previous 2D models. Such modeling enables the prediction of the macroscopic transport properties over the entire range of water activity (or water content) and to quantify their corresponding impact on the moisture loss. These transport properties can further be upscaled for use in continuum models of fruit drying processes (Datta 2007; Datta et al. 2012; Aregawi et al. 2014; Defraeye \& Verboven 2016).

The sorption isotherm and the tissue permeability (and effective diffusivity) calculated using the proposed model are comparable with the experimental results given in the literature, for all dehydration cases considered. Although the plasmolysis case sorption curve lies below that of the experimental data, the average value of the water content over the three dehydration cases lies within the range of the experimental data. These results hint that the co-existence of different dehydration mechanisms are 
essential to be taken into account, although further study is needed to determine the exact proportion of each case at a given dehydration condition. The shape of the simulated (weighted average) and experimental sorption curves follow the type III sorption isotherms commonly found in food that contains sugar (Labuza \& Altunakar 2007). The equilibrium water content decreases steeply at high water activity but slowly at low water activity. The ability of apple tissue to transport water is decreasing as the cells are being dehydrated. This is indicated by the reduced tissue permeability. Even when accounting for the counteracting effect of shrinkage of the tissue, so transport pathway, the water flux was reduced, as identified by the MTC. As such, the dehydrated cell is less permeable to water transport, compared to fresh tissue, for the same water potential gradient. Therefore, in the case of convective drying, the dehydrated cells near the fruit-air interface create additional barriers to further water removal from the fresh tissue, and thereby slow down the drying kinetics.

The sensitivity of the tissue permeability to the variation of the cell shape (cuboctahedron and cylinder) is not significant. The simulation shows that the elongation ratio has a more significant impact on the tissue permeability than the change of the cell shape. An elongated cell has a higher permeability than a cell with low elongation ratio because in the former case, water is transported mainly through the protoplast. The parametric study suggests that at high water activity, the cell membrane acts as the primary barrier to water transport, limiting the water transport out of the cell protoplast. On the other hand, the cell wall has a dominant role at lower water activity levels since it has a low permeability within this range. The cell size has a positive impact on the tissue permeability, while the dry matter density of the protoplast is not a key factor in determining the tissue permeability. Furthermore, the study on the plasmolysis mechanisms (complete or attached) shows that the cell permeability is higher when the protoplast is attached to the side of the cell wall that is parallel to the water transport direction. Nevertheless, different plasmolysis mechanisms do not affect the tissue permeability at a low water potential as the protoplast volume becomes very small compared to the total cell volume.

Although the presented model is adequate to predict the macroscopic water transport properties of fruit tissue during the entire de- hydration process, some improvements are yet to be developed. In the 
proposed 3D model, it is assumed that the cells have the same shape and are regularly arranged. The stochastic nature of the cell geometry is therefore neglected. The model can be improved by adopting real 3D cell geometries for a more realistic representation of the fruit cellular structure. Such geometries can be obtained by using non-destructive imaging techniques, for instance X-ray computed tomography of fruit tissue (Ting et al. 2013; Herremans, Verboven, Verlinden, et al. 2015). 


\section{Conclusions}

By explicitly quantifying the impact of changes in the cellular structure (free shrinkage, plasmolysis and lysis) during dehydration of an apple parenchyma tissue, the developed 3D model gives new insights in water transport at the cellular scale which was not possible before. It enabled to identify the fruit tissue dehydration process down to very low water activities. Simulations show that the macroscopic transport properties of apple tissue, i.e. the tissue sorption isotherm and water permeability, have a high dependency on the way in which the cellular structure changes. Apple tissue with cells that undergo plasmolysis has a sorption isotherm curve below the ones of free shrinkage or lysis. Because of the increase in intracellular space volume, plasmolysis reduces the tissue equilibrium water content up to $60 \%$ compared to free shrinkage or lysis, at the same water activity level. Lysis increases the tissue water permeability up to five times compared to the other two cases. We identified that the dehydrated, shrunken cellular tissue reduces the outgoing water flux, compared to fresh tissue, for the same water potential gradient. As such, dehydrated tissue forms a kind of barrier against further moisture removal from the fresh tissue below, and thereby slows down the drying kinetics. With this model, the role of each cellular component and the cell geometry on the tissue water transport properties is also identified. Factors that have a high impact on the tissue water permeability are the membrane permeability coefficient, the cell wall thickness, the cell size and the elongation aspect ratio of the cell. Although the calculated values for tissue sorption isotherm and water permeability are within the typical values found in experiments, the model can be still further improved. This includes, amongst others, extracting the geometry from real fruit tissue, for ex- ample by using non-destructive imaging techniques such as Xray tomography. Although the work presented in this study only focuses on apple fruit, the conceptual methodology can also be applied to other fruits to derive their macroscopic water transport properties. 


\section{Acknowledgement}

We acknowledge the support of the Swiss National Science Foundation SNSF (project 200021_160047).

\section{Reference}

Abera, M.K. et al., 2013. Virtual Fruit Tissue Generation Based on Cell Growth Modelling. Food and Bioprocess Technology, 6(4), pp.859-869.

Aregawi, W. a. et al., 2014. Prediction of water loss and viscoelastic deformation of apple tissue using a multiscale model. Journal of physics: Condensed Matter, 26(46), p.464111. Available at: http://www.ncbi.nlm.nih.gov/pubmed/25347182.

Bal, L.M. et al., 2010. Drying kinetics and effective moisture diffusivity of bamboo shoot slices undergoing microwave drying. International Journal of Food Science and Technology, 45(11), pp.2321-2328.

Ben-Arie, R., Kislev, N. \& Frenkel, C., 1979. Ultrastructural changes in the cell walls of ripening apple and pear fruit. Plant Physiology, 64(2)(2), pp.197-202.

Bidhendi, A.J. \& Geitmann, A., 2016. Relating the mechanics of the primary plant cell wall to morphogenesis. Journal of Experimental Botany, 67(2), pp.449-461.

Bonet, J. \& Wood, R.D., 2008. Nonlinear Continuum Mechanics for Finite Element Analysis, Available at: http://ebooks.cambridge.org/ref/id/CBO9780511755446.

CBI, 2008. Preserved Fruit and Vegetables: The EU Market for Dried Fruit. CBI Market Information Database, pp.1-22.

Constenla, D.T., Lozano, J.E. \& Crapiste, G.H., 1989. Thermophysical Properties of Clarified Apple Juice as a Function of Concentration and Temperature. Journal of Food Science, 54(3), pp.663668.

Coulson, J.. et al., 1999. Fluid Flow, Heat Transfer and Mass Transfer. In Chemical Engineering. Elsevier B.V., pp. 381-409.

Datta, A.K., 2007. Porous media approaches to studying simultaneous heat and mass transfer in food processes. II: Property data and representative results. Journal of Food Engineering, 80(1), pp.96- 
110.

Datta, A.K. et al., 2012. Soft matter approaches as enablers for food macroscale simulation. Faraday Discussions, 158, p.435.

Defraeye, T. \& Verboven, P., 2016. Convective drying of fruit: role and impact of moisture transport properties in modelling. Journal of Food Engineering, 193, pp.95-107. Available at: http://dx.doi.org/10.1016/j.jfoodeng.2016.08.013.

Devahastin, S. \& Niamnuy, C., 2010. Modelling quality changes of fruits and vegetables during drying: A review. International Journal of Food Science and Technology, 45(9), pp.1755-1767.

Eichner, K., 1975. The Influence of Water Content on Non-enzymic Browning Reactions in Dehydrated Foods and Model Systems and the Inhibition of Fat Oxidation by Browning Intermediates. In R. Duckworth, ed. Water Relations of Foods. ACADEMIC PRESS INC., pp. 417-434. Available at: http://dx.doi.org/10.1016/B978-0-12-223150-6.50029-8.

Fanta, S.W. et al., 2013. Microscale modeling of water transport in fruit tissue. Journal of Food Engineering, 118(2), pp.229-237. Available at: http://dx.doi.org/10.1016/j.jfoodeng.2013.04.003.

Fanta, S.W. et al., 2012. Water transport properties of artificial cell walls. Journal of Food Engineering, 108(3), pp.393-402. Available at: http://dx.doi.org/10.1016/j.jfoodeng.2011.09.010.

Ferrando, M. \& Spiess, W.E.L., 2001. Cellular response of plant tissue during the osmotic treatment with sucrose, maltose, and trehalose solutions. Journal of Food Engineering, 49(2-3), pp.115-127.

Ferrando, M. \& Spiess, W.E.L., 2002. Transmembrane mass transfer in carrot protoplasts during osmotic treatment. Journal of Food Science, 67(7), pp.2673-2680.

Gibson, L.J., 2012. The hierarchical structure and mechanics of plant materials. Journal of The Royal Society Interface, 9(76), pp.2749-2766.

Halder, A., Datta, A.K. \& Spanswick, R.M., 2011. Water transport in cellular tissues during thermal processing. AIChE Journal, 57(9), pp.2574-2588. Available at: http://doi.wiley.com/10.1002/aic.12465 [Accessed October 22, 2016].

Haynes, W.M., 2014. CRC Handbook of Chemistry and Physics, 95th Edition, 2014-2015,

Herremans, E., Verboven, P., Verlinden, B.E., et al., 2015. Automatic analysis of the 3-D microstructure of fruit parenchyma tissue using X-ray micro-CT explains differences in aeration. BMC plant 
biology, 15(1), p.264. Available at: http://www.biomedcentral.com/1471-2229/15/264.

Herremans, E. et al., 2013. Characterisation of "Braeburn" browning disorder by means of X-ray microCT. Postharvest Biology and Technology, 75, pp.114-124. Available at: http://dx.doi.org/10.1016/j.postharvbio.2012.08.008.

Herremans, E., Verboven, P., Hertog, M.L.A.T.M., et al., 2015. Spatial development of transport structures in apple (Malus $\times$ domestica Borkh.) fruit. Frontiers in Plant Science, 6(September), p.679.

Ho, Q.T. et al., 2014. A Multiphase Pore Scale Network Model of Gas Exchange in Apple Fruit. Food and Bioprocess Technology, 7(2), pp.482-495.

Ho, Q.T. et al., 2013. Multiscale modeling in food engineering. Journal of Food Engineering, 114(3), pp.279-291. Available at: http://dx.doi.org/10.1016/j.jfoodeng.2012.08.019.

Holz, M., Heil, S.R. \& Sacco, A., 2000. Temperature-dependent self-diffusion coefficients of water and six selected molecular liquids for calibration in accurate 1H NMR PFG measurements. Physical Chemistry Chemical Physics, 2(20), pp.4740-4742.

Joardder, M.U.H. et al., 2015. Effect of Cell Wall Properties on Porosity and Shrinkage of Dried Apple. International Journal of Food Properties, 18(10), pp.2327-2337. Available at: http://www.tandfonline.com/doi/full/10.1080/10942912.2014.980945.

Karunasena, H.C.P. et al., 2014. A coupled SPH-DEM model for micro-scale structural deformations of plant cells during drying. Applied Mathematical Modelling, 38(15-16), pp.3781-3801.

Karunasena, H.C.P. et al., 2014. A particle based model to simulate microscale morphological changes of plant tissues during drying. Soft matter, 10(29), pp.5249-5268. Available at: http://www.ncbi.nlm.nih.gov/pubmed/24740612.

Karunasena, H.C.P. et al., 2015. Application of meshfree methods to numerically simulate microscale deformations of different plant food materials during drying. Journal of Food Engineering, 146, pp.209-226.

Kaya, A., Aydin, O. \& Demirtaş, C., 2007. Drying Kinetics of Red Delicious Apple. Biosystems Engineering, 96(4), pp.517-524.

Khan, A.A. \& Vincent, J.F. V, 1990. Anisotropy of apple parenchyma. Journal of the Science of Food 
and Agriculture, 52(4), pp.455-466.

Krokida, M.K. \& Maroulis, Z.B., 1997. Effect of Drying Method on Shrinkage and Porosity. Drying Technology, 15(10), pp.2441-2458. Available at: http://www.tandfonline.com/doi/abs/10.1080/07373939708917369.

Labuza, T.P., 1972. Nutrient losses during drying and storage of dehydrated foods. C R C Critical Reviews in Food Technology, 3(2), pp.217-240.

Labuza, T.P. \& Altunakar, B., 2007. Water activity prediction and moisture sorption isotherms. In Water activity in foods: Fundamentals and applications. pp. 109-154.

Lang, I. et al., 2014. Plasmolysis: Loss of Turgor and Beyond. Plants, 3(4), pp.583-593. Available at: http://www.mdpi.com/2223-7747/3/4/583/.

Lewicki, P.P. \& Pawlak, G., 2003. Effect of drying on microstructure of plant tissue. Drying Technology, 21(4), pp.657-683. Available at: http://www.tandfonline.com/doi/abs/10.1081/DRT120019057.

Lewicki, P.P. \& Porzecka-Pawlak, R., 2005. Effect of osmotic dewatering on apple tissue structure. Journal of Food Engineering, 66, pp.43-50.

Lin, T.-T. \& Pitt, R.E., 1986. Rheology of Apple and Potato Tissue As Affected By Cell Turgor Pressure. Journal of Texture Studies, 17(3), pp.291-313.

Maurel, C., 1997. Aquaporins and Water Permeability of Plant Membranes. Annual Review of Plant Physiology and Plant Molecular Biology, 48(1), pp.399-429. Available at: http://www.annualreviews.org/doi/10.1146/annurev.arplant.48.1.399.

Mayor, L. \& Sereno, A.M., 2004. Modelling shrinkage during convective drying of food materials: A review. Journal of Food Engineering, 61(3), pp.373-386.

Mebatsion, H.K. et al., 2009. A novel method for 3-D microstructure modeling of pome fruit tissue using synchrotron radiation tomography images. Journal of Food Engineering, 93(2), pp.141-148. Available at: http://dx.doi.org/10.1016/j.jfoodeng.2009.01.008.

Mebatsion, H.K. et al., 2008. Modelling fruit (micro)structures, why and how? Trends in Food Science and Technology, 19(2), pp.59-66.

Moshelion, M., Moran, N. \& Chaumont, F., 2004. Dynamic changes in the osmotic water permeability 
of protoplast plasma membrane. Plant Physiology, 135(August), pp.2301-2317. Available at: http://www.plantphysiol.org/content/135/4/2301.

Mossel, D.A.A., 1975. Water and Micro-organisms in Foods-A Synthesis R. Duckworth, ed., ACADEMIC PRESS INC. Available at: http://linkinghub.elsevier.com/retrieve/pii/B9780122231506500250.

Naiqian, W. \& Pitts, M.J., 1999. Development and validation of a finite element model of an apple fruit cell. Postharvest Biology and Technology, 16, pp.1-8.

Nobel, P.S., 2009. Physicochemical and environmental plant physiology, Academic Press. Available at: http://www.sciencedirect.com/science/book/9780123741431 [Accessed August 23, 2017].

Omolola, A.O., Jideani, A.I.O. \& Kapila, P.F., 2015. Quality Properties of Fruits as Affected by Drying Operation. Critical reviews in food science and nutrition, 57(May), pp.37-41. Available at: http://www.ncbi.nlm.nih.gov/pubmed/25675260.

Oparka, K.J., 1994. Plasmolysis: New insights into an old process. New Phytologist, 126(67), pp.571591.

Perera, C.O., 2005. Selected Quality Attributes of Dried Foods. Drying Technology, 23(4), pp.717-730.

Ramirez, C. et al., 2011. Microstructure analysis on pre-treated apple slices and its effect on water release during air drying. Journal of Food Engineering, 106(3), pp.253-261.

Rathnayaka Mudiyanselage, C.M. et al., 2017. Novel trends in numerical modelling of plant food tissues and their morphological changes during drying - A review. Journal of Food Engineering, 194, pp.24-39.

Ratti, C., 2001. Hot air and freeze-drying of high-value foods: A review. Journal of Food Engineering, 49(4), pp.311-319.

Seguí, L. et al., 2006. Mass transfer phenomena during the osmotic dehydration of apple isolated protoplasts (Malus domestica var. Fuji). Journal of Food Engineering, 77(1), pp.179-187.

Seguí, L., Fito, P.J. \& Fito, P., 2010. Analysis of structure-property relationships in isolated cells during OD treatments. Effect of initial structure on the cell behaviour. Journal of Food Engineering, 99(4), pp.417-423. Available at: http://dx.doi.org/10.1016/j.jfoodeng.2009.05.019.

van der Sman, R., 2015. Hyperelastic models for hydration of cellular tissue. Soft Matter, 11, pp.7579- 
7591. Available at: http://pubs.rsc.org/en/Content/ArticleLanding/2015/SM/C5SM01032B.

Ting, V.J.L. et al., 2013. X-ray micro-computer tomographic method to visualize the microstructure of different apple cultivars. Journal of Food Science, 78(11).

Tortoe, C., Orchard, J. \& Beezer, A., 2008. Artificial cell studies in simulated apple and potato starch cell complex during osmotic dehydration. Journal of Food Quality, 31(5), pp.559-570. Available at: http://doi.wiley.com/10.1111/j.1745-4557.2008.00220.x.

Vega-Galvez, A. et al., 2012. Effect of temperature and air velocity on drying kinetics, antioxidant capacity, total phenolic content, colour, texture and microstructure of apple (var. Granny Smith) slices. Food Chemistry, 132(1), pp.51-59.

Velić, D. et al., 2004. Influence of airflow velocity on kinetics of convection apple drying. Journal of Food Engineering, 64(1), pp.97-102.

Yamaki, S., 1984. Isolation of vacuoles from immature apple fruit flesh and compartmentation of sugars, organic acids, phenolic compounds and amino acids. Plant and Cell Physiology, 25(1), pp.151-166.

Younis, M., Abdelkarim, D. \& Zein El-Abdein, A., 2018. Kinetics and mathematical modeling of infrared thin-layer drying of garlic slices. Saudi Journal of Biological Sciences, 25(2), pp.332-338. Available at: https://www.sciencedirect.com/science/article/pii/S1319562X1730178X [Accessed June 26, 2018].

Zlatanović, I., Komatina, M. \& Antonijević, D., 2013. Low-temperature convective drying of apple cubes. Applied Thermal Engineering, 53(1), pp.114-123. 


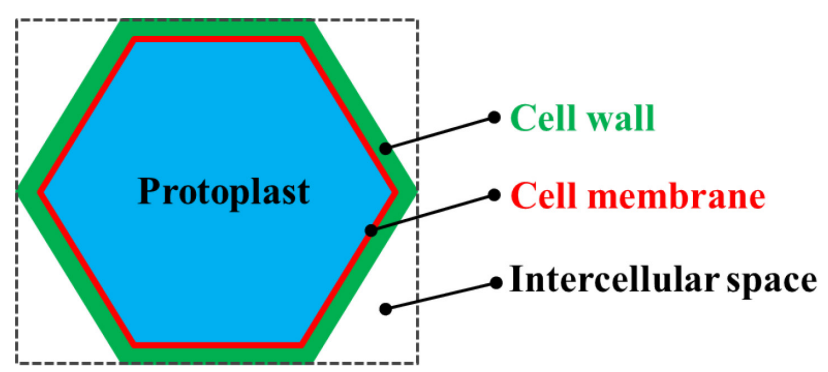

Fig. 1. Schematic of fruit cellular structure. 


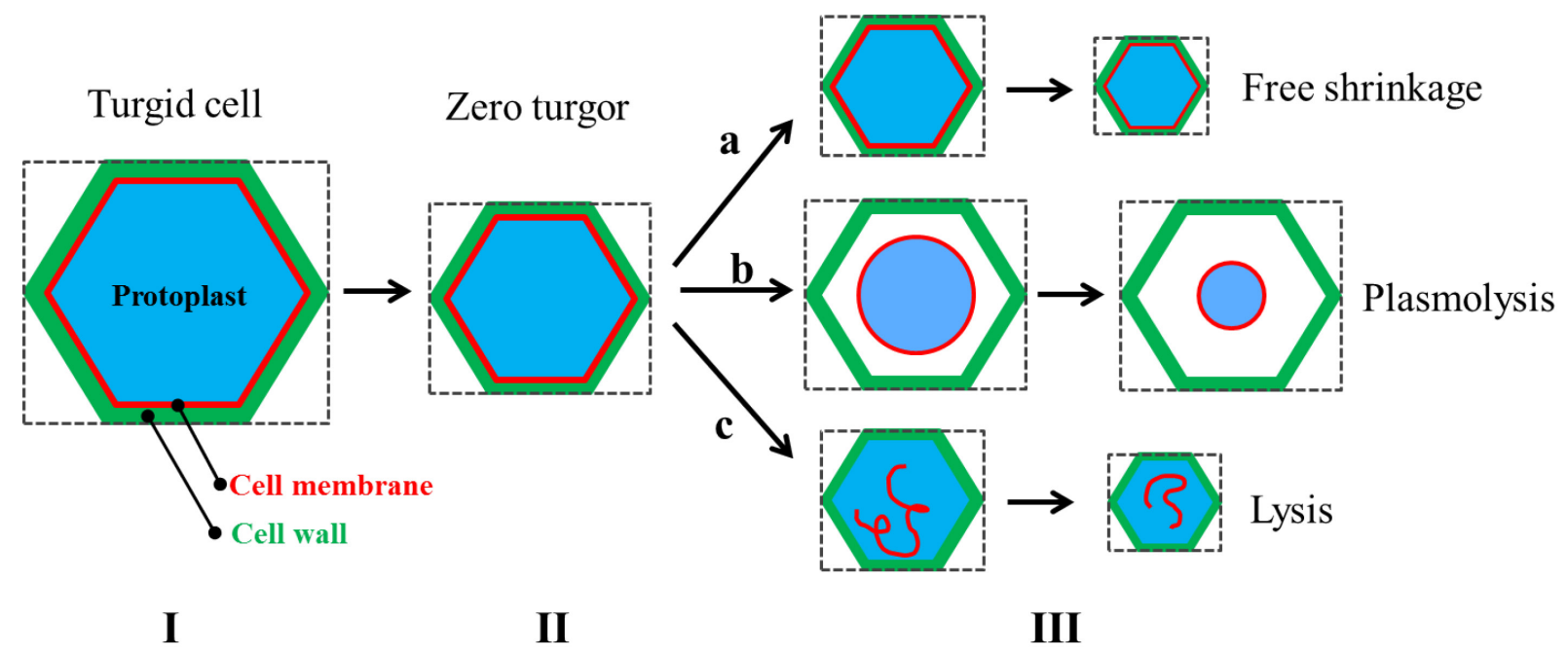

Fig. 2. Schematic of the cell dehydration mechanisms. First, a turgid cell (I) shrinks to zero turgor point (II). Subsequently, the cell may undergo free shrinkage (IIIa), plasmolysis (IIIb) or lysis (IIIc). 


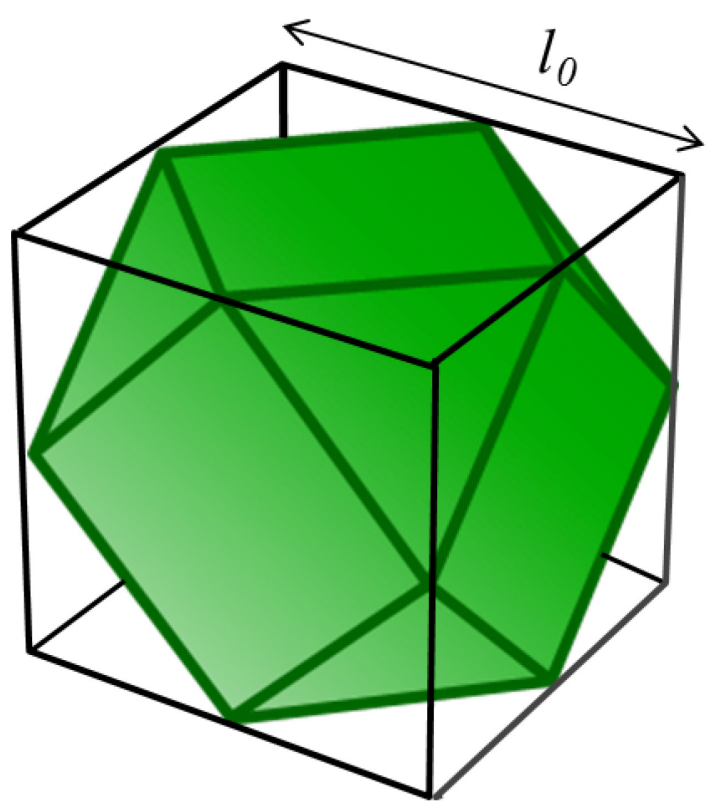

Fig. 3. Apple parenchyma cell, modeled as a cuboctahedron and delimited by a cube. $l_{0}$ is the initial edge length of the cuboctahedron. 


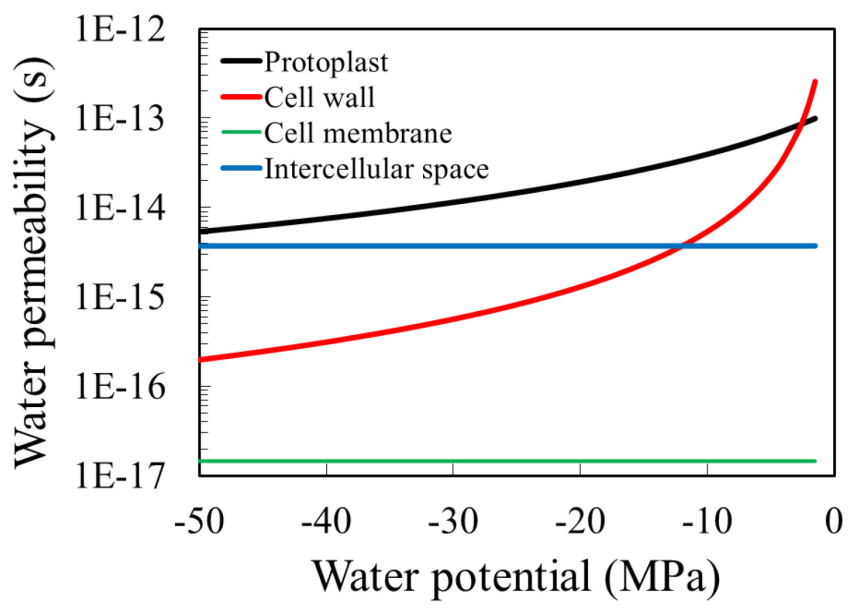

Fig. 4. Permeability of cellular components of apple fruit as a function of water potential. 


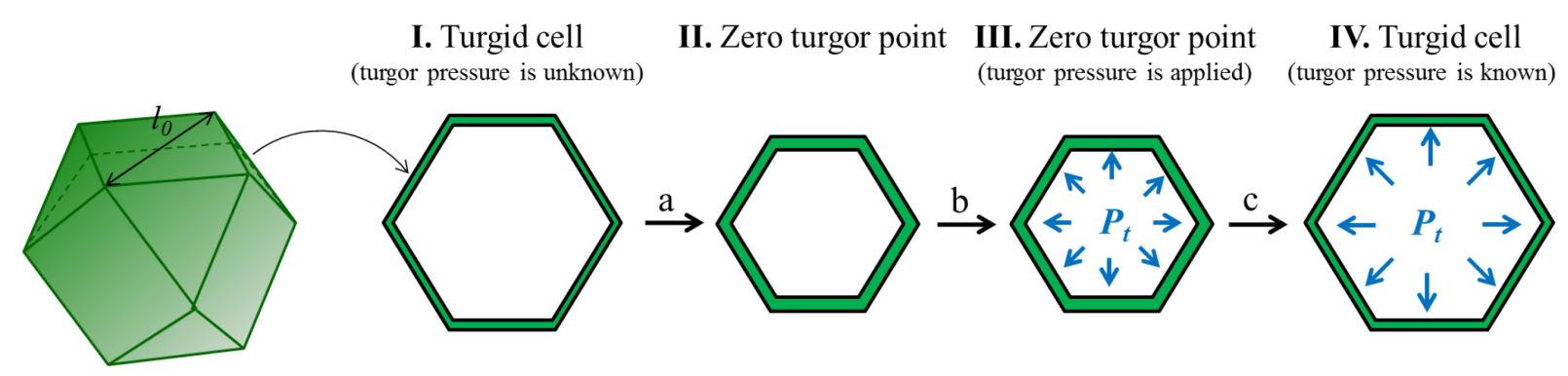

Fig. 5. Procedure to determine the turgor pressure in a cell: a fresh cell (I) is shrunken to zero turgor point (II) after which the turgor pressure $P_{T}$ is applied uniformly to the cell wall, from 0 (III) to 1 MPa (IV). 


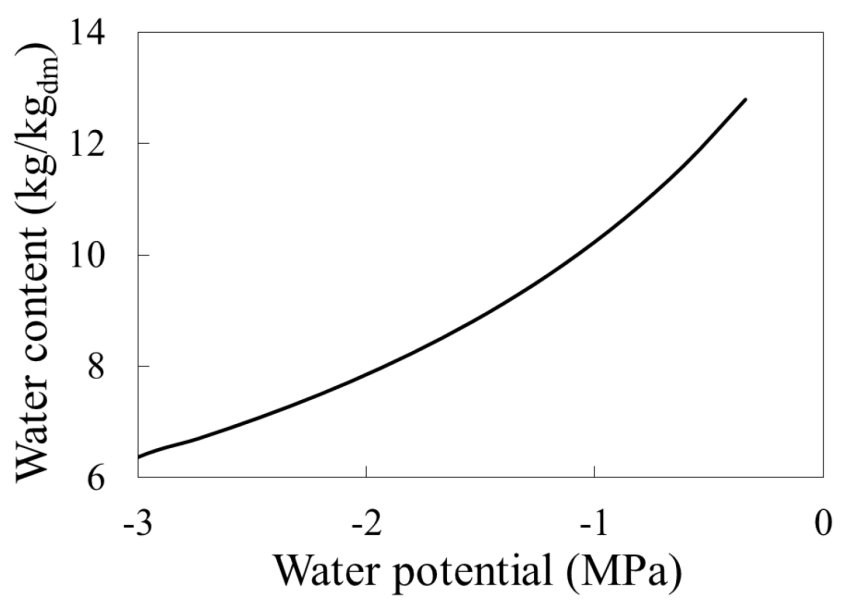

Fig. 6. Sorption isotherm of the protoplast under turgid conditions. 


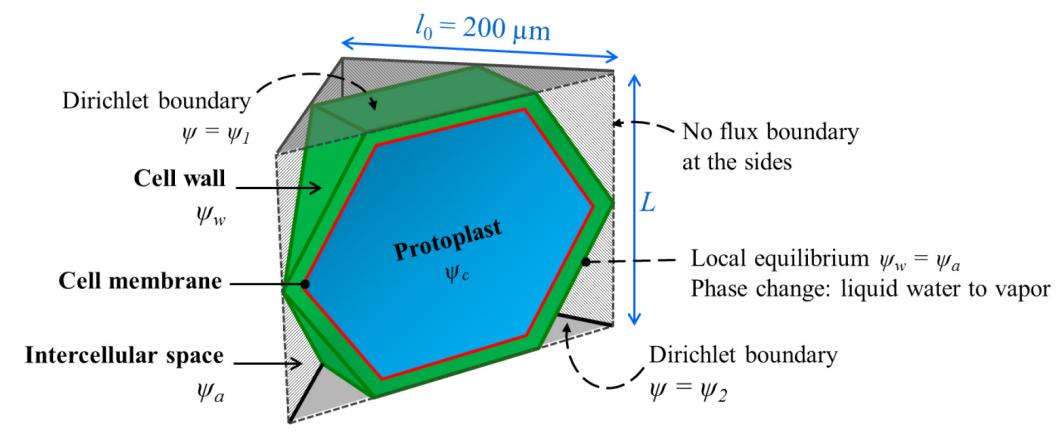

Fig. 7. Schematic representation of the computation domain of the cellular structure and indication of the boundary conditions. 
(a) Cuboctahedron

$$
\mathrm{a}=1
$$

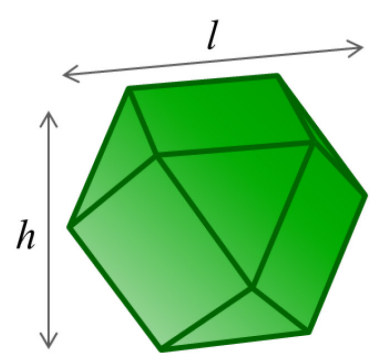

(b) Cylinder

$a=0.5$

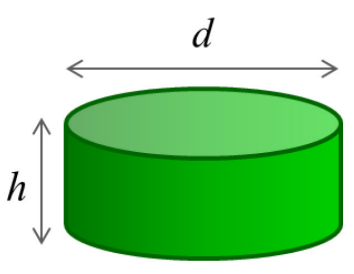

(c) Cylinder $a=1$

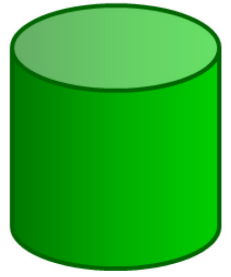

(d) Cylinder $a=2$

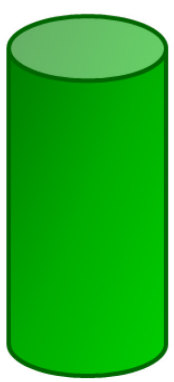

Fig. 8. Geometrical variation of the cell structure: (a) cuboctahedron (base case) and cylinders with elongation ratio $a$ of (b) 1 , (c) 2 and (d) 4 . 
(a) Complete plasmolysis

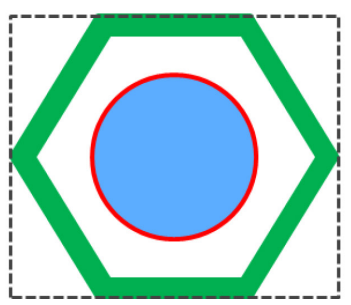

(b) Bottom-attached plasmolysis

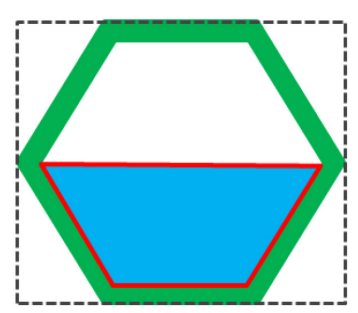

(c) Side-attached plasmolysis

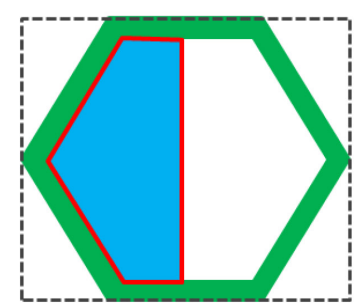

Fig. 9. Diagonal cross-sectional representations of the cellular structure: (a) complete plasmolysis case and partial plasmolysis cases with protoplast attachment: (b) at the bottom and (c) at the side of the cell wall at $a_{w}=0.958$. 


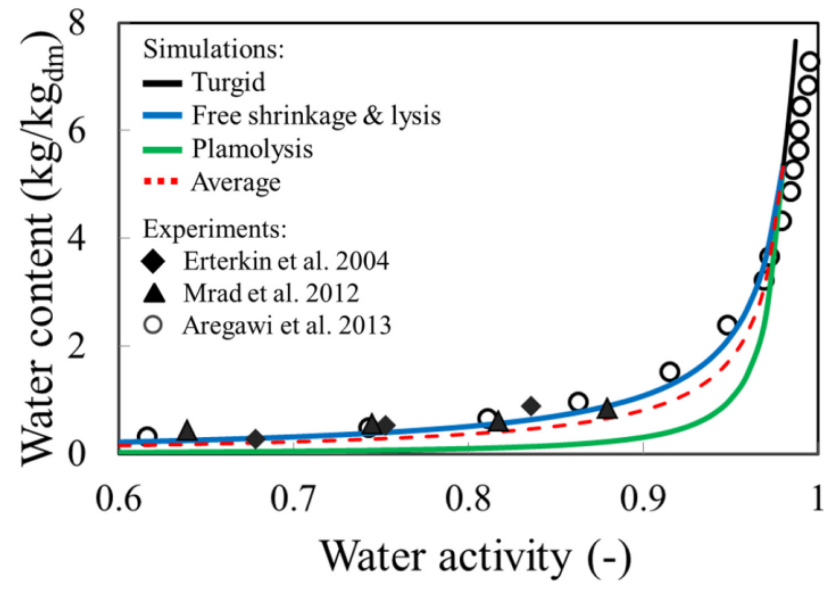

Fig. 10. Comparison of apple tissue sorption isotherms from the microscale model considering different cases of cell dehydration after the cell loses its turgidity (free shrinkage, plasmolysis, lysis, and their weighted average) and from experiments (Kaymak-Ertekin and Gedik, 2004; Mrad et al., 2012; Aregawi et al., 2013). 

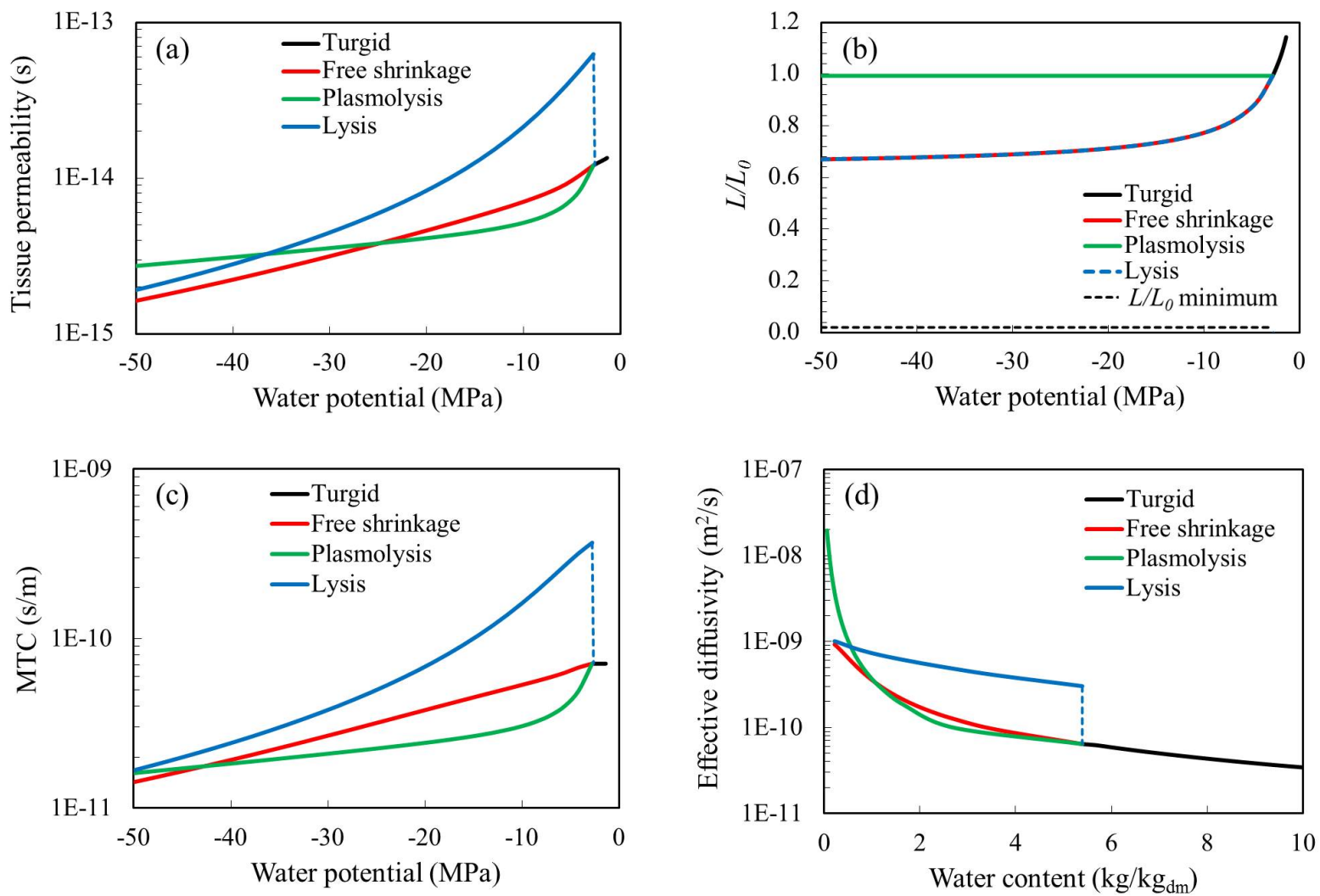

Fig. 11. Impact of different dehydration cases on (a) the tissue permeability $K$, (b) the ratio of the deformed cell length $L$ to the initial length $L_{0}$, (c) the mass transfer coefficient MTC and (d) the effective diffusivity. 


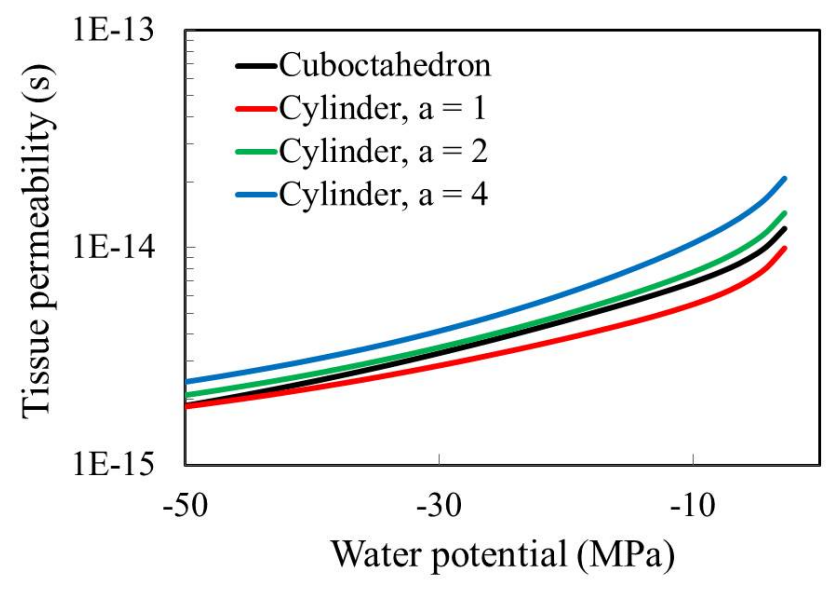

Fig. 12. Tissue permeability for different cell geometries (cuboctahedron and cylinders of varying elongation aspect ratios). 
(a) Impact of membrane permeability $P_{m}$

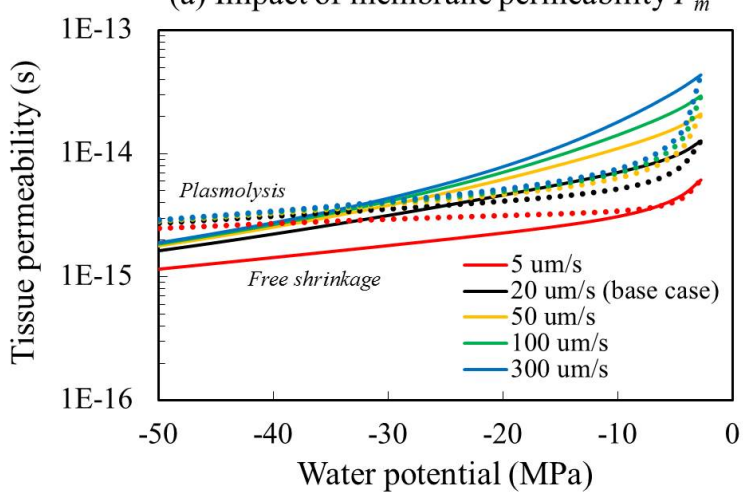

(c) Impact of dry matter density of protoplast $\rho_{d m, c}$

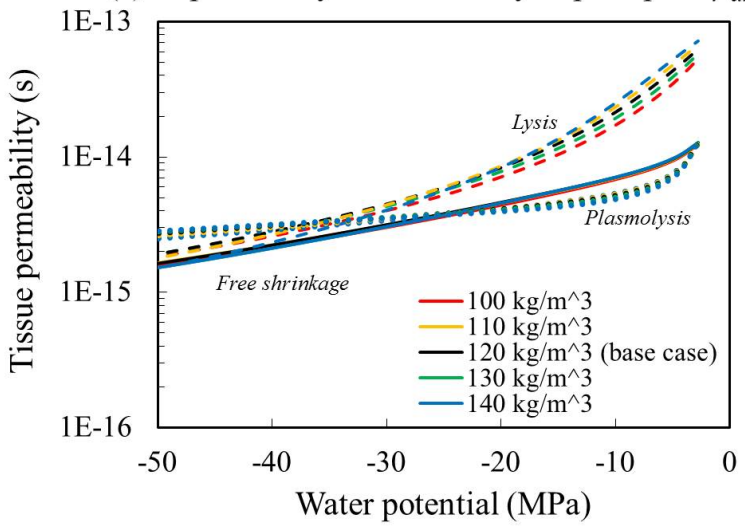

(b) Impact of cell wall thickness $t_{w}$

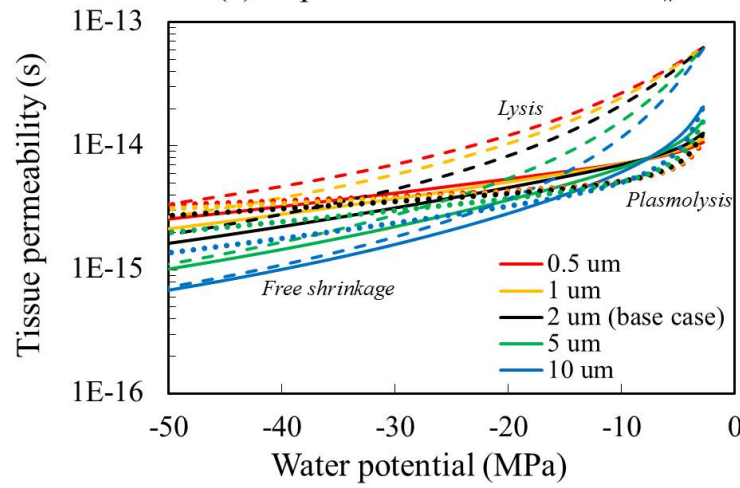

(d) Impact of initial cell edge length $l_{0}$

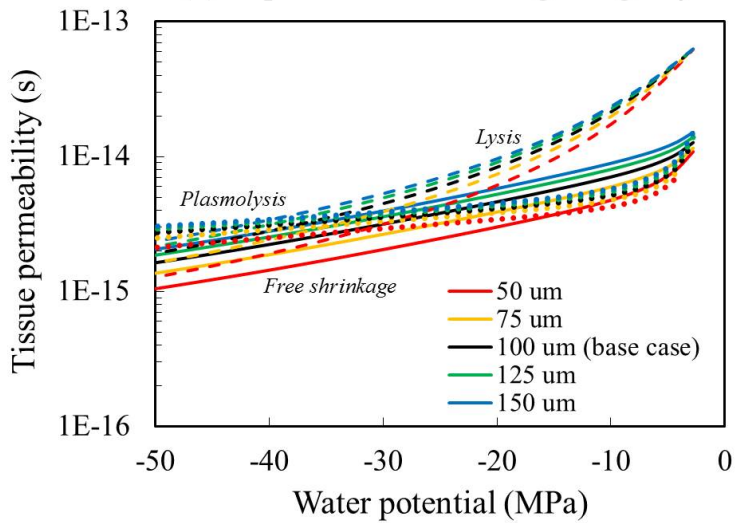

Fig. 13. Impact of (a) membrane permeability coefficient, (b) cell wall thickness, (c) dry matter density of the protoplast and (d) initial cell radius on the tissue permeability in the free shrinkage (solid lines), plasmolysis (dotted lines) and lysis (dashed lines) cases. 


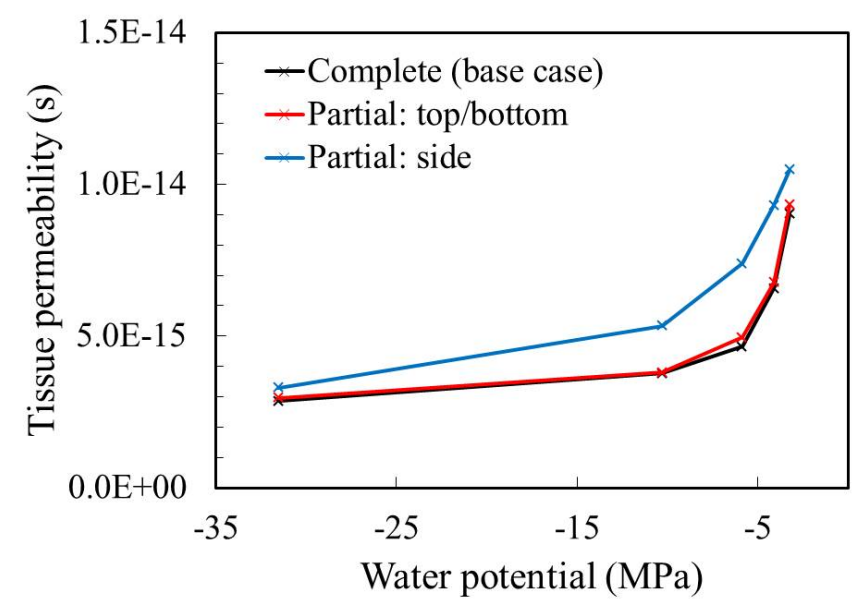

Fig. 14. Tissue permeability for different plasmolysis mechanisms: complete plasmolysis (base case) and partial plasmolysis with protoplast attached to the top/bottom and the side of the cell wall. 
Table 1. Material properties, model parameters and boundary conditions

\begin{tabular}{|c|c|c|c|}
\hline Material property & Value & Unit & Reference \\
\hline Water diffusivity of protoplast, $D_{c}$ & $2.2 \times 10^{-9}$ & $\mathrm{~m}^{2} / \mathrm{s}$ & (Holz et al. 2000) \\
\hline Water diffusivity of cell wall, $D_{w}$ & $4.19 \times 10^{-10}$ & $\mathrm{~m}^{2} / \mathrm{s}$ & (Fanta et al. 2012) \\
\hline Water diffusivity of intercellular air space, $D_{a}$ & $2.42 \times 10^{-5}$ & $\mathrm{~m}^{2} / \mathrm{s}$ & (Haynes 2014) \\
\hline Dry matter density of protoplast, $\rho_{d m, c}$ & 120 & $\mathrm{~kg} / \mathrm{m}^{3}$ & (Constenla et al. 1989) \\
\hline Dry matter density of cell wall, $\rho_{d m, w}$ & 58.035 & $\mathrm{~kg} / \mathrm{m}^{3}$ & (Fanta et al. 2012) \\
\hline Dry matter density of intercellular air space, $\rho_{d m, a}$ & 1.184 & $\mathrm{~kg} / \mathrm{m}^{3}$ & (Coulson et al. 1999) \\
\hline Water capacity of air, $C_{\psi, a}$ & $1.3 \times 10^{-10}$ & $1 / \mathrm{Pa}$ & (Coulson et al. 1999) \\
\hline Membrane permeability coefficient, $P_{m}$ & $2 \times 10^{-5}$ & $\mathrm{~m} / \mathrm{s}$ & $\begin{array}{l}\text { (Ferrando \& Spiess 2001; } \\
\text { Moshelion et al. 2004) }\end{array}$ \\
\hline Desorption isotherm parameter of cell wall, $\alpha$ & 0.147 & & (Fanta et al. 2012) \\
\hline Desorption isotherm parameter of cell wall, $\gamma$ & 1.00 & & (Fanta et al. 2012) \\
\hline Desorption isotherm parameter of cell wall, $R_{c}$ & 0.9495 & & (Fanta et al. 2012) \\
\hline Molar mass of solutes, $M_{s}$ & 0.203 & $\mathrm{~kg} / \mathrm{mol}$ & (Tortoe et al. 2008) \\
\hline Molar volume of water, $V_{w}$ & $1.8 \times 10^{-5}$ & $\mathrm{~m}^{3} / \mathrm{mol}$ & \\
\hline Initial edge length, $l_{0}$ & 200 & $\mu \mathrm{m}$ & $\begin{array}{c}\text { (Herremans, Verboven, Verlinden, } \\
\text { et al. 2015) }\end{array}$ \\
\hline Initial water content, $x_{c, 0}$ & 6.54 & & Experimental result \\
\hline Initial cell wall thickness, $t_{w, 0}$ & 2 & $\mu \mathrm{m}$ & $\begin{array}{l}\text { (Joardder et al. 2015; Mebatsion et } \\
\text { al. 2009; Ben-Arie et al. 1979) }\end{array}$ \\
\hline
\end{tabular}


Table 2. Maximum and minimum value of tissue permeability, MTC, and effective diffusivity at different dehydration cases. Inside the parentheses is the water activity at which the value occurs.

\begin{tabular}{lcccccc}
\hline \multirow{2}{*}{ Dehydration case } & \multicolumn{2}{c}{ Permeability $(\mathbf{s})$} & \multicolumn{2}{c}{ MTC (s/m) } & \multicolumn{2}{c}{ Diffusivity $\left(\mathrm{m}^{2} / \mathbf{s}\right)$} \\
& Max. & Min. & Max. & Min. & Max. & Min. \\
\hline \multirow{2}{*}{ Turgid } & $1.35 \times 10^{-14}$ & $1.22 \times 10^{-14}$ & $7.12 \times 10^{-11}$ & $7.12 \times 10^{-11}$ & $6.42 \times 10^{-11}$ & $3.17 \times 10^{-11}$ \\
& $(0.99)$ & $(0.97)$ & $(0.99)$ & $(0.97)$ & $(0.97)$ & $(0.99)$ \\
Free Shrinkage & $1.21 \times 10^{-14}$ & $1.58 \times 10^{-15}$ & $7.12 \times 10^{-11}$ & $1.38 \times 10^{-11}$ & $8.47 \times 10^{-10}$ & $6.42 \times 10^{-11}$ \\
& $(0.97)$ & $(0.60)$ & $(0.97)$ & $(0.60)$ & $(0.60)$ & $(0.97)$ \\
Plasmolysis & $1.21 \times 10^{-14}$ & $2.70 \times 10^{-15}$ & $7.12 \times 10^{-11}$ & $1.58 \times 10^{-11}$ & $1.35 \times 10^{-08}$ & $6.42 \times 10^{-11}$ \\
& $(0.97)$ & $(0.60)$ & $(0.97)$ & $(0.60)$ & $(0.60)$ & $(0.97)$ \\
Lysis & $6.26 \times 10^{-14}$ & $1.85 \times 10^{-15}$ & $3.68 \times 10^{-10}$ & $1.61 \times 10^{-11}$ & $9.79 \times 10^{-10}$ & $3.03 \times 10^{-10}$ \\
& $(0.97)$ & $(0.60)$ & $(0.97)$ & $(0.60)$ & $(0.60)$ & $(0.97)$ \\
\hline
\end{tabular}

